\title{
Valorization of Date Palm Wastes by Lignin Extraction to be Used for the Improvement of Polymeric Membrane Characteristics
}

\author{
Adel Zrelli ${ }^{1,2^{*}}$, Walid Elfalleh" ${ }^{1,2}$, Achraf Ghorbal ${ }^{1}$, Bechir Chaouachi \\ ${ }^{1}$ Higher Institute of Applied Sciences and Technology of Gabes, University of Gabes, 6072 Gabes, Omar Ibn. ElKhattab St., Tunisia \\ 2 Laboratory of Energy, Water, Environment and Process, LR18ES35, National Engineering School of Gabes, 6072 Gabes, Omar \\ Ibn. ElKhattab St., Tunisia \\ * Corresponding author, e-mail: adel.zrelli@issatgb.u-gabes.tn
}

Received: 29 March 2021, Accepted: 18 June 2021, Published online: 08 November 2021

\begin{abstract}
This work aimed to valorize Date Palm Wastes (DPW) by the extraction of lignin and its application for polymeric membrane modification. Lignin was extracted from five types of DPW (date palm kernel, leaflet, pedicel, palm frond, and fibrilium) using the Klason method. Following DPW characterization, we remark the highest amount of extractives content in the leaflet sample (10.07 \%) and the lowest in the fibrilium sample (6.51 \%). The ash content ranged from $1.56 \%$ for fibrilium to $7.96 \%$ for palm frond. After extraction, the lignin yield was in the range of 22-32\%. The extracted lignins were characterized by Infrared and Ultraviolet-visible spectroscopy. All extracted lignins provide a high concentration of (-OH) group. Besides, both syringyl and guaiacyl are present in the extracted lignins with a slightly more syringyl unit. The extracted lignins were added to the polymeric solution, prepared from waste plastic, to produce membranes. These membranes showed improved hydrophilicity marked a decrease in the contact angle of $28 \%$ when the lignin concentration increased from 0.125 to $0.5 \%$. In addition, the membrane porosity increased with the use of the extracted lignins as an additive.
\end{abstract}

Keywords

valorization, DPW, lignin, waste plastic, membrane, characterization

\section{Introduction}

The oasis of Gabes (Tunisia) is the unique marine oasis located along the Mediterranean coast and one of the last such oasis in the world. This coastal oasis is home to more than 510,000 palm trees [1]. According to Chandrasekaran and Bahkali [2], date trees produce large quantities of Date Palm Wastes (DPW). Based on one estimate, each date palm tree produces about $20 \mathrm{~kg}$ of dry leaflet yearly. Other wastes such as date palm kernel represent an average of $10 \%$ of the date fruits [2]. Another estimation was quantified the annual DPW to $35 \mathrm{~kg}$ per date palm [3] and approximately the amount of wastes in the coastal oasis of Gabes is around 20,000 tons annually (153,000 tons annually in Tunisia). Given the availability of this DPW in large quantities, it can be used as a cheap and feasible substrate for its transformation into valuable products and consequently the reduction of environmental pollution. Many uses of this DPW can be envisaged. Among which food and agriculture uses including the composting of these waste to produce organic fertilizer [4], the use of this waste as biofuel to prepare food, and as animal feed. In other context, DPW is incorporated in a cement matrix to increase its thermal insulation. As a result, the thermal insulation increased by $77 \%$ with the addition of $5 \%$ of DPW to the cement [5]. This DPW have promising applications since it is composed mainly of cellulose (30.2\%), hemicelluloses (14.8\%), lignin (26.4\%), and other compounds that could be used in many processes [6]. Cellulose can be considered as the most abundant natural polymer on earth. It can be used in water retention and as a suspension stabilizer in many industries such as food, pharmaceuticals, and cosmetics. In addition, it can be transformed into high-value products, polymer composites. Lignin is the second most abundant polymer from plants after cellulose. It acts as natural glue that links cellulose and hemicellulose. It has a omplex polymeric structure and the potential to produce chemicals with high value [7-10]. In general, 
the extraction of lignin from DPW can be done by different methods, such as the Kraft method and the Organosolv method [11]. Hochegger et al. [12] studied the influence of the reaction temperature on lignin properties, they found that when the temperature was maintained at $187^{\circ} \mathrm{C}$, the obtained lignin has high content of phenolic hydroxyl group. But, when compared content of phenolic hydroxyl group in Kraft lignin to Organosolv lignin, the Kraft lignin presents the highest content [11]. When Kraft lignin was compared to Organosolv lignin, the lignin extracted by the Organosolv method showed a predominance of syringyl and guaiacyl units but the Kraft lignin has better thermal stability [13]. Besides, the Organosolv lignin was sulfur free, which in contrast is still present in the Kraft lignin. To use simple, cheaper, and faster extraction method of lignin from DPW, Klason method was selected since it meets these requirements. Also, the Klason method is considered as a robust technique for extracting lignin from DPW [6]. Besides, the Klason method allows to obtain higher lignin yield and the obtained lignin has elevated higher heating values [14]. Many uses of lignin can be distinguished such as the use of lignin as a precursor for the production of biofuels [6]. Also, lignin can be used as corrosion inhibitors [15]. The fields in which lignin can be used are different such as adsorption, food pharmaceutical, composites, cosmetic industries, and membrane preparation [16]. The preparation of polymer membranes from natural materials or waste is an emerging area of research [17, 18]. Many studies have focused on this area. Among these studies, Park et al. [19] have developed a thin-film composite from sustainable resources such as waste recycled polymers, plant-based monomers, and green solvents. The membrane obtained exhibits excellent performance compared to that prepared with toxic reagents.

This work aims to valorize the DPW (date palm kernel, palm frond, leaflet, pedicel, and fibrilium) by lignin extraction using the Klason method. Then, the extracted lignins were characterized by FT-IR and UV-vis. To the best of the authors' knowledge, this is the first study on the application of Klason lignin, obtained from DPW, as an additive to waste low-density polyethylene (LDPE) for membrane preparation by inversion phase process. The effects of adding lignin on membrane characteristics will be presented.

\section{Materials and methods}

\subsection{Materials}

In this work, we used five DPW. These wastes are date palm kernel, leaflet Pedicel, palm frond, and fibrilium (Fig. 1).

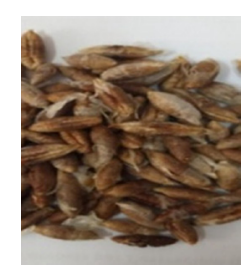

(a)

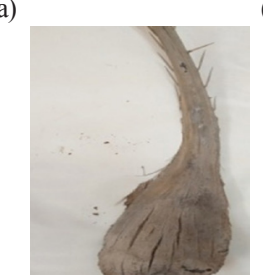

(d)

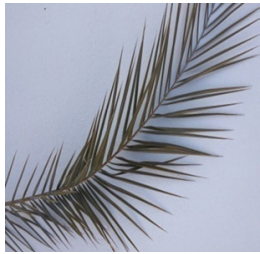

(b)

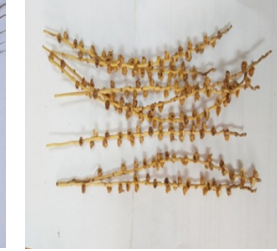

(c)

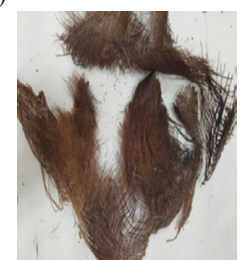

(e)
Fig. 1 Samples of Date Palm Waste used in this work: (a) date palm kernel, (b) leaflet, (c) pedicel, (d) palm frond and (e) fibrilium

The samples of this DPW were grounded using laboratory grinder (FW-135, Tester Co., LTD, Tianjin, China) to obtain uniform size. To eliminate long and medium fibers, the particle size distribution was performed using a set of standard sieves. These used sieves had openings among 420-1000 $\mu \mathrm{m}$ (35 and 16 mesh). Particles larger than $1000 \mu \mathrm{m}$ and lower than $420 \mu \mathrm{m}$ were not considered for tests.

\subsection{Characterization of the used DPW}

The characterization of the used DPW involved determining the ash content, moisture content, density, soluble extractives as well as holocellulose content.

We determine the ash content in the DPW according to the ASTM D2866-94 [20]. The moisture content is determined following ASTM D2216-98 [21]. The density of DPW was evaluated based on the ISO 8962 using a pycnometer [22]. To determine of the soluble extractives, the TAPPI T212 om-98 standard was followed. The method presented by ASTM D1104-56-78 (1985) for the determination of holocelluloses was used [23].

\subsection{Extraction of lignin}

The used method to extract lignin is the Kason method. This method is composed of two major steps. One is to remove the extractives from the DPW (Fig. 1), while the other is to treat the residue obtained by sulfuric acid. In the first step, we have used the TAPPI methods- T $204 \mathrm{~cm}-97$ [24]. In this method, we extract DPW samples with ethanolbenzene to make them extractive-free (waxes, oils, resins, gums). In this case, we avoid the presence of these extractive materials in the extracted lignin which, causes an overestimation of Klason lignin content and may influence the quality of the produced lignin. A sample 
of $5 \pm 0.001 \mathrm{~g}$ of DPW $(150-250 \mu \mathrm{m})$ was extracted with $150 \mathrm{ml}$ of ethanol-benzene $(1 / 2 \mathrm{v} / \mathrm{v})$ for 5 hours with a minimum boiling in a Soxhlet. The residue of the extraction was washed with ethanol to remove benzene. This residue was extracted by the addition of $400 \mathrm{~mL}$ of hot water in a water bath for three hours. Therefore, the residue was filtered, washed with ethanol, dried at $105 \pm 3{ }^{\circ} \mathrm{C}$ for one hour, cooled in a desiccator, and weighed to determine the percentage of extractive in each sample of DPW. Then, this DPW sample free of extractive was treated with $72 \%$ $\mathrm{H}_{2} \mathrm{SO}_{4}$ at $37{ }^{\circ} \mathrm{C}$ for two hours. The obtained mixture was diluted with water to $3 \% \mathrm{H}_{2} \mathrm{SO}_{4}$, and then boiled under reflux for 4 hours. The hydrolyzed residue was filtered, dried in an oven at $105 \pm 1{ }^{\circ} \mathrm{C}$ for one hour and cooled in a desiccator and weighed. The yield of lignin production (h) was determined by Eq. (1).

$\eta=\frac{m_{\text {lignin }}}{m_{\text {waste }}} \times 100$,

where $m_{\text {lignin }}$ is the weight of the obtained lignin $(\mathrm{g})$, and $m_{\text {waste }}$ is the weight of the sample of DPW (g).

\subsection{Characterization of the lignin samples}

\subsubsection{Fourier Transformed Infrared spectroscopy}

We used in this work a Spectrum Two (PerkinElmer, USA) FTIR spectrometer with a deuterated tri-glycine sulphate (DTGS) pyroelectric detector. The spectrometer was equipped with a diamond Attenuated Total Reflectance (ATR) accessory. Spectra were recorded in the wavenumbers range of 450-4000 $\mathrm{cm}^{-1}$ by an average of 4 scans at a spectral resolution of $2 \mathrm{~cm}^{-1}$.

\subsubsection{Ultraviolet (UV) spectrophotometric}

UV-visible spectra of the obtained lignin were achieved using UV-visible spectrophotometry with PG instruments $\mathrm{T} 80$ spectrophotometer. The absorbance range was chosen based on the work of Latif et al. [25]. For our case, we measured the absorbance within the 190-400 nm spectral range using a $0.05 \mathrm{~nm}$ spectral resolution. Also, we kept constant the concentration of the sample in solution (1.5 mg of sample in $5 \mathrm{ml} \mathrm{NaOH} \mathrm{2M)} \mathrm{[26].}$

Based on the work of Jablonsky et al. [27], the amount in $\mathrm{mmol} / \mathrm{g}$ of non-conjugated $(N-$ conj $)$, conjugated (Conj) and total of phenolic groups (Total) can be calculated by:

Non-conjugated phenolic hydroxyl $(N-c o n j)$ :

$N-c o n j=\frac{\left(0.250 A_{300}+0.0595 A_{350}\right)}{c d}$.
Conjugated phenolic hydroxyl (Conj):

Conj $=\frac{0.0476 A_{350}}{c d}$.

Total amount of phenolic hydroxyl (Total):

Total $=\frac{\left(0.250 A_{300}+0.107 A_{350}\right)}{c d}$,

where $A_{300}$ and $A_{350}$ : absorbance at 300 and $350 \mathrm{~nm}, c$ : mass concentration $\left(\mathrm{g} \mathrm{l}^{-1}\right)$ and $d$ : path length through the sample $(\mathrm{cm})$.

\subsection{Membrane preparation}

Many configurations of membranes can be seen such as hollow fiber membranes or flat membranes [28]. In this study, we prepared flat membranes from a waste of low density polyethylene (LDPE) as described elsewhere [29]. In this case, the used chemical method for the membranes preparation is the phase inversion in which we used as solvent the xylene and as anti-solvent the ethanol. Sigma Aldrich (Milan, Italy) supplied all these materials. The polymeric solution was obtained from a mixture of $10 \%$ LDPE and $90 \%$ xylene by heating at $110{ }^{\circ} \mathrm{C}$ for $2 \mathrm{~h}$. To distinguish the effect of lignin on membrane properties, we added the obtained lignin in the range of $0.125-0.5 \%$ to the polymeric solution. The obtained polymeric solution was then casted on glass and we fixed the thickness of the casting at $400 \mu \mathrm{m}$. Then, we immersed the casted film in the anti-solvent bath composed of ethanol at $293 \mathrm{~K}$. Due to this immersion, the inversion phase took place and the membrane was detached from the glass. After water washing, we dried the obtained membrane in an oven at $323 \mathrm{~K}$ overnight and then at $298 \mathrm{~K}$ for $24 \mathrm{~h}$. We performed the membranes characterization to investigate the effect of the lignin addition.

\subsection{Membrane characterization}

\subsubsection{Membrane porosity}

To elucidate the relationship between the addition of lignin and the membrane porosity $(\varepsilon)$, we determined the porosity of the prepared membrane using Eq. (5) [30].

$\varepsilon(\%)=\frac{\left(W_{w}-W_{d}\right) \rho_{p}}{\left(W_{w}-W_{d}\right) \rho_{p}+W_{d} \rho_{i}} 100 \%$,

where is $W_{d}$ the mass of the dry membrane $(\mathrm{g}), W_{w}$ is the mass of the wet membrane $(\mathrm{g}), \rho_{p}$ is the LDPE density $\left(\mathrm{g} \mathrm{cm}^{-3}\right)$ and $\rho_{i}$ is the isobutanol density $\left(\mathrm{g} \mathrm{cm}^{-3}\right)$. 


\subsubsection{Contact angle and SEM of membrane}

The hydrophilicity or the hydrophobicity of the membrane can be assessed following the measurement of the contact angle. These measurements were performed with KRÜSS Drop Shape Analyzer - DSA25 and the determination of the contact angle was done using Advance software. The surface morphology observations of membranes were made using the SEM employing an XL30 device (Philips Co., Netherlands) operated at $25 \mathrm{kV}$ accelerating potential.

\section{Results and discuss}

\subsection{Raw material characterization}

Fig. 2 summarizes the chemical composition and the physical properties of the five samples of Date Palm Wastes, which are date palm kernel, palm frond, fibrilium, leaflet, and pedicel. Fig. 2 (a) showed the ash content in DPW, which is the amount of inorganic substituent present in the carbon. As noticeable, the values of ash are between $1.86 \pm 0.2 \%$ for fibrilium and $4.58 \pm 0.02 \%$ for pedicel. For the date palm kernel we obtained a value of $2.58 \pm 0.4 \%$ which is higher than that obtained by Salomón-Torres et al. (1.42\%) [31]. According to Li et al. [32], less quantity of ash in DPW contributes to a high yield of lignin. In our case, due to the lower ash value in fibrilium and palm frond (1.86 $\pm 0.2 \%$, $1.96 \pm 0.3 \%$ ) their lignin yield may be the highest.

Moreover, the values of moisture content in the DPW have been depicted in Fig. 2 (b). As seen, a significantly higher moisture content was observed in palm frond and fibrilium. The lowest moisture content was from the leaflet $(4.3 \pm 0.52 \%)$ which was significantly lower than the date palm kernel and pedicel. The value of the moisture

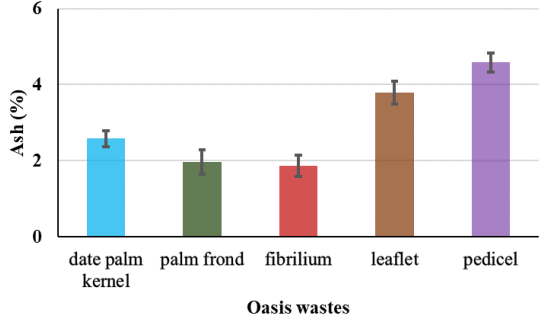

(a)

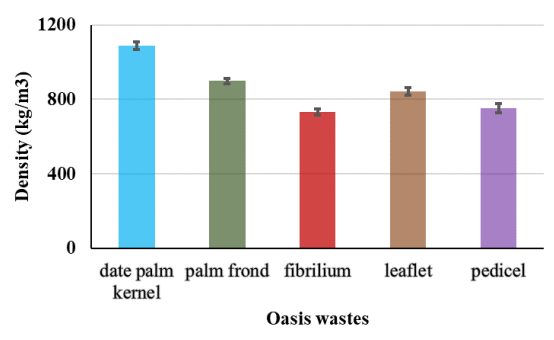

(c)

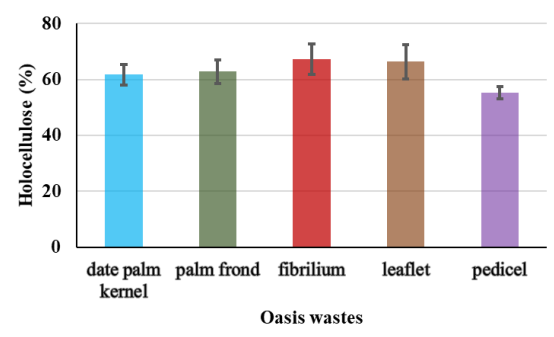

(d) (b)

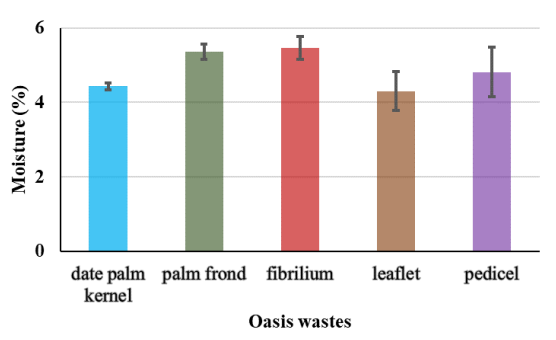

content in date palm kernel is $4.43 \pm 0.09 \%$, which is near the lowest value of the range [3.1\%, $12.5 \%]$ presented by Hossain et al. [33].

The values of DPW density were presented in Fig. 2(c) The density of date palm kernel is $1090 \pm 9.75 \mathrm{~kg} \mathrm{~m}^{-3}$ which is the highest value of the five DPW samples. The obtained density value of date palm kernel is similar to that obtained by Kolawole et al. [34] which is $1140 \mathrm{~kg} \mathrm{~m}^{-3}$.

Fig. 2 (d) showed the holocellulose composition of these five samples. The holocellulose content of the samples ranged from $55.21 \pm 2.1 \%$ for pedicel to $67.29 \pm 5.4 \%$ for fibrilium. Nevertheless, it can be noted that holocellulose content in fibrilium is relatively high when compared to holocellulose content in other samples. The high content of holocellulose in fibrilium is also observed by Almi et al. [35] and Bousdira et al. [36]. For the case of the holocellulose content in date palm kernel, the obtained value which is $61.7 \%$ is lower than those obtained by Bouchelta et al. [37]. According to the obtained results, the content of holocellulose in the DPW is compatible with the reported holocellulose content in hardwoods and softwoods [32]. This content of holocellulose in the DPW was higher which allows easier lignin extraction [38].

According to Pecha and Garcia-Perez [39], extractives include fats, phenolics, resin acids, waxes, and inorganics. Fig. 2 (e) shows the extractives contained in the five DPW samples. The highest value of extractives was obtained using the leaflet sample, which is $10.07 \pm 0.74 \%$. Similar levels of extractives, of the analyzed DPW, were presented by Chaari et al. [40], Senthil Kumar and Yaashikaa [41], and Jabli et al. [42]. Some authors have found that extractives are

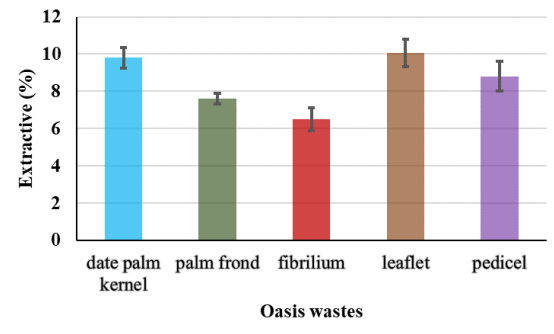

(e)

Fig. 2 Evaluation of (a) Ash content, (b) Moisture, (c) Density, (d) holocellulose and (e) extractive in the Date Palm wastes 
known to change the properties of lignin [39]. According to Demirbaş et al. [43], the extracted lignin from different parts of softwoods and hardwoods differ slightly in composition such as the degree of carbon-carbon linkage between phenyl groups and methoxyl substitution. Also, the lignin content in hardwoods, softwoods, and non-wood influences positively the higher heating value [44]. Based on the finding of da Silva et al. [45], which found that high extractive content increases its higher heating value and the quantity of the extracted lignin from DPW.

\subsection{Yield of lignin production}

Fig. 3 presents the obtained lignins by the Klason method and from five types of DPW. These lignins were weighed and the biopolymer production yield was calculated. Fig. 3 presents the evolution of this yield with the DPW. According to this figure, the lignin yield is ranged between 22 and $32 \%$. We noted that date palm frond has the highest lignin content with a mass yield of about $32 \%$. Similar results have been reported by other authors, where the lignin yield was in the range of 21.70-35.89\% [6].

\subsection{Chemical structure of the extracted lignin from DPW}

FTIR of the five samples of the lignin extracted from DPW and the lignin purchased from Sigma were presented in Fig. 4. The FT-IR spectra are for each extracted lignin from DPW. These spectra are different only in terms of band intensities. Moreover, in the spectra of several samples, some bands are missed, weak, medium, or intense in the same region. The obtained lignin spectra highlight two important regions, such as the bands of the region $3400-1800 \mathrm{~cm}^{-1}$ and bands from $1800-800 \mathrm{~cm}^{-1}$ which is the region of fingerprint attributed primarily to syringyl and guaiacyl structural units, but also to other functional groups. Fig. 5 shows a great similarity in the region between 3400 and $1800 \mathrm{~cm}^{-1}$. All spectra showed a large band, around $3350 \mathrm{~cm}^{-1}$, due to the stretching vibration of hydroxyl groups $(\mathrm{OH})$ bonded to hydrogen.

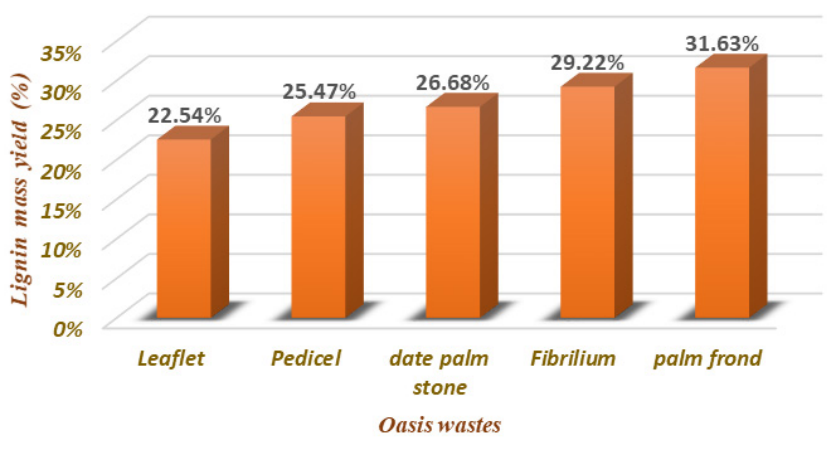

Fig. 3 Lignin mass yield as a function of Date Palm Waste
This large band indicates that for all studied samples, the lignin structure contains a high concentration of the group $\mathrm{OH}$. Latif et al. [25] indicated this same finding. In addition, the stretching vibrations of the aromatic $\mathrm{C}-\mathrm{H}$ valence in methylene, methoxyl, and methyl groups were observed, in all samples, between 2800 and $3000 \mathrm{~cm}^{-1}$. However, a peak with weak intensity for the lignin obtained from fibrilium and leaflet was observed. For the case of Sigma, pedicel, and palm frond, a peak with moderate intensity was obtained. Furthermore, only the peak of lignin obtained from date palm kernel have a strong intensity, which indicates that the lignin structure would contains a high concentration of monomers than the other four samples. This can be correlated with a large number of syringyl units. The $1800-800 \mathrm{~cm}^{-1}$ "fingerprint" containing various bands at the following wavenumbers: $1700 \mathrm{~cm}^{-1}, 1600 \mathrm{~cm}^{-1}, 1510 \mathrm{~cm}^{-1}, 1460 \mathrm{~cm}^{-1}, 1424 \mathrm{~cm}^{-1}$, $1356 \mathrm{~cm}^{-1}, 1275 \mathrm{~cm}^{-1}, 1215 \mathrm{~cm}^{-1}, 1160 \mathrm{~cm}^{-1}, 1115 \mathrm{~cm}^{-1}$, $1030 \mathrm{~cm}^{-1}, 850 \mathrm{~cm}^{-1}$, and $810 \mathrm{~cm}^{-1}$. The peak assigned to unconjugated carbonyl stretching can be shown in all studied samples around $1700 \mathrm{~cm}^{-1}$. The peaks have small intensity values for fibrilium and palm frond, and moderate intensity for the other samples which means that the unconjugated carbonyl group is present in lignin at a low to moderate intensity. The stretching vibration of the aromatic ring in lignin showed converged peaks with weak intensity for palm frond at $1607 \mathrm{~cm}^{-1}$ and for fibrilium at $1604 \mathrm{~cm}^{-1}$, and moderate peak intensity for the other samples. This same observation was noted for the peaks around $1510 \mathrm{~cm}^{-1}$. These bands provide a means of recognizing the aromatic structure of lignin. Fig. 5 showed that the lignin extracted from date palm kernel has more aliphatic $\mathrm{CHx}$ groups with respect to the aromatic $\mathrm{CH}$ groups. For the other samples, the aliphatic content of $\mathrm{CHx}$ is slightly higher than that of aromatics [26]. Moderate intensities peaks showen at $1460 \mathrm{~cm}^{-1}$ for all obtained samples, except pedicel, date palm kernel, and lignin from Sigma revealed strong intensities peaks. This band was assigned to $\mathrm{C}-\mathrm{H}$ deformations in syringyl derivatives.

Bending vibration of $\mathrm{OH}$ in phenolic bonds have an absorption peak only for date palm kernel (at $1359 \mathrm{~cm}^{-1}$ ) and lignin from Sigma (at $1369 \mathrm{~cm}^{-1}$ ). This means that the phenolic group (-OH) disappears in the majority of lignin samples due to the probability of the formation of free radical intermediates from the site of the phenolic group $(-\mathrm{OH})$ which consumes these groups and configures the ether bonds [46]. The bands at $1270 \mathrm{~cm}^{-1}$, assigned to guaiacyl ring breathing, C-O stretch in lignin, $\mathrm{C}-\mathrm{O}$ linkage in guaiacyl aromatic methoxyl groups. Fig. 4 showed convergent peaks values with strong intensity for fibrilium sample (at $1267 \mathrm{~cm}^{-1}$ ) and sigma sample (at $1264 \mathrm{~cm}^{-1}$ ). Furthermore, moderate 


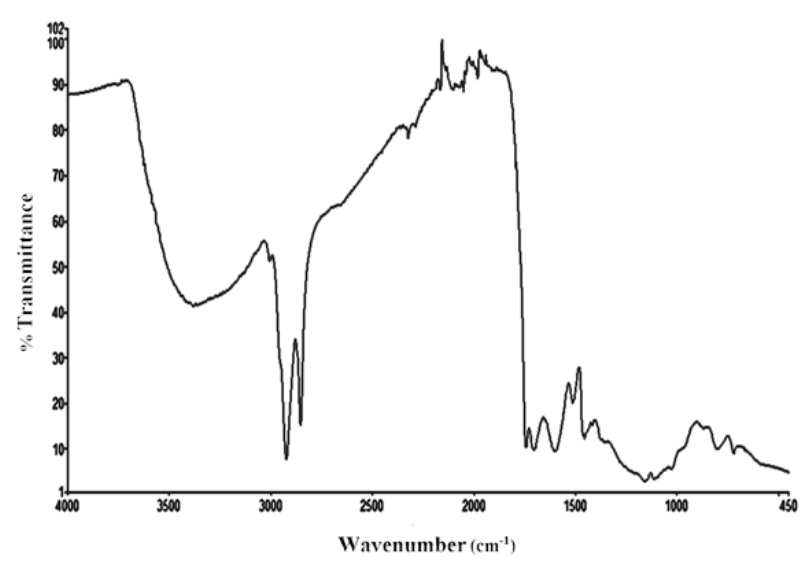

(a)

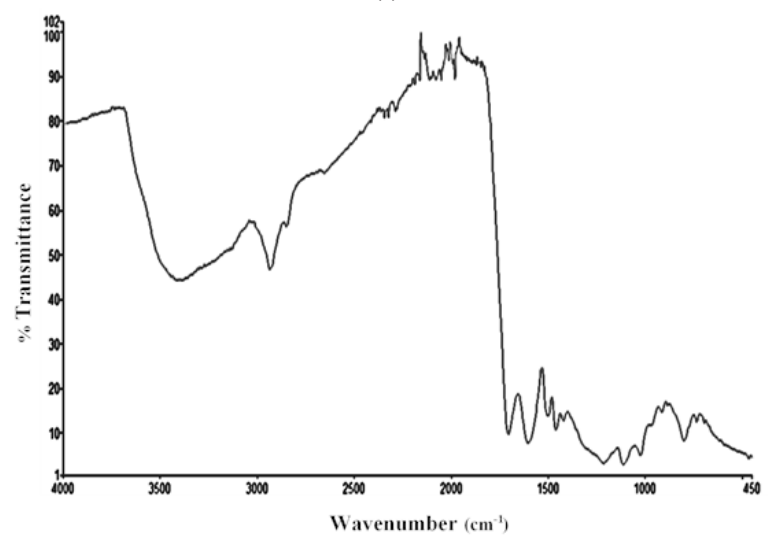

(c)

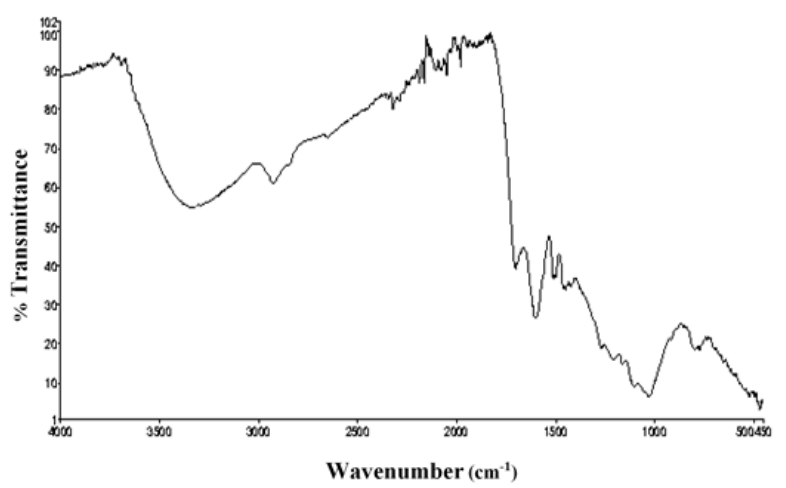

(e)

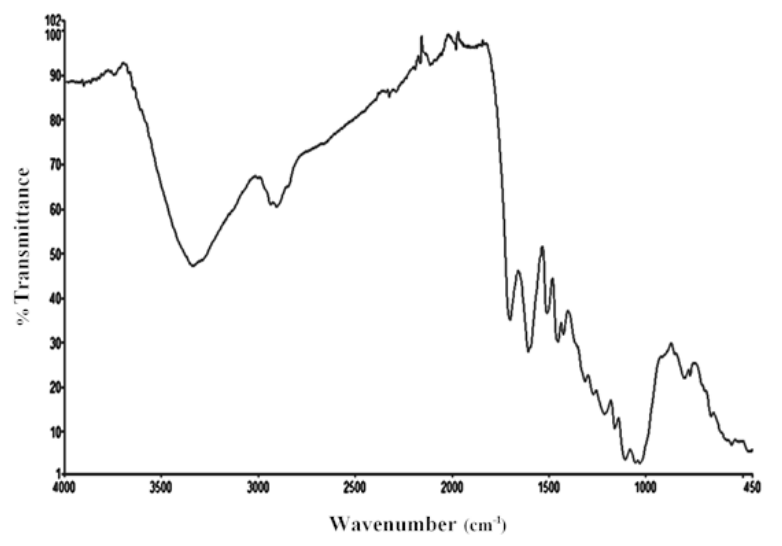

(b)

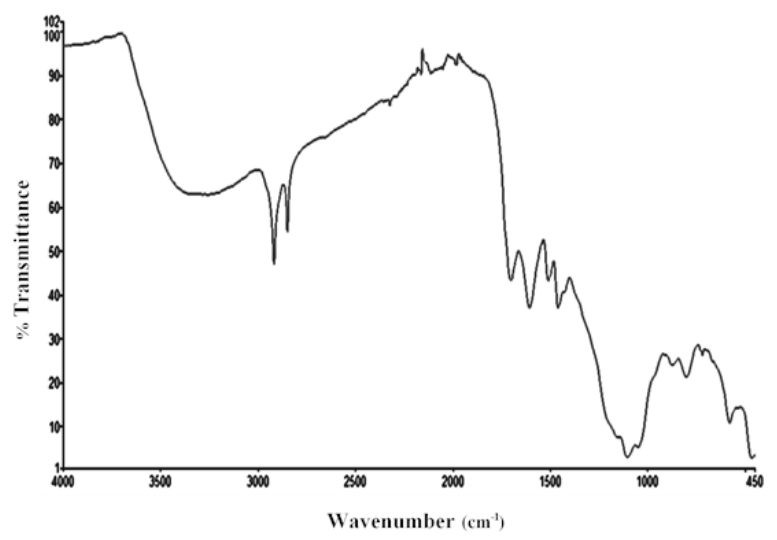

(d)

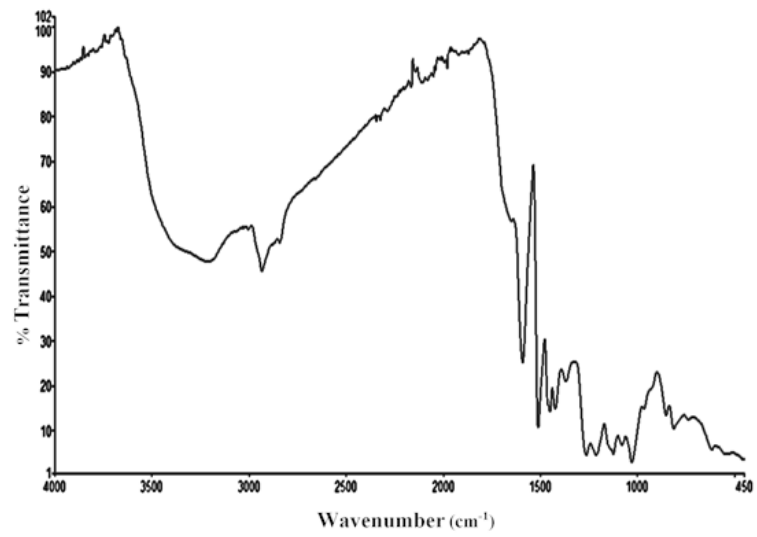

(f)

Fig. 4 FT-IR spectra of (a) date palm kernel, (b) leaflet, (c) pedicel, (d) palm frond (e) fibrilium, (f) sigma

intensity can be seen for the leaflet sample at $1271 \mathrm{~cm}^{-1}$. According to Fig. 6, all the studied lignin exhibited a ratio of syringyl to guaiacyl (S/G) up to $87 \%$, which is the same things presented by Safou-Tchiama et al. [47]. The obtained lignins from DPW are composed of significantly more syringyl units than the lignin from sigma. In addition, the (S/G) of the obtained lignins were almost twice as high as the $\mathrm{S} / \mathrm{G}$ of the sigma lignin. The pedicel and sigma samples showed convergent peaks with strong intensity at 1215 and
$1211 \mathrm{~cm}^{-1}$ respectively. This peak was assigned to the $\mathrm{C}-\mathrm{O}$ stretching in syringyl unit. The aromatic $\mathrm{C}-\mathrm{H}$ deformation of syringyl unit at $1110 \mathrm{~cm}^{-1}$ showed peaks with strong intensities for all studied samples. This indicates its strong concentration of the syringyl in all samples. A strong signal was observed at $1030 \mathrm{~cm}^{-1}$ for all studied lignin samples. This band was related to the $\mathrm{C}-\mathrm{O}$ stretching of syringyl unit of lignin which has a high concentration in all samples of lignin [48]. The C-H bending of syringyl unit was seen at bands 


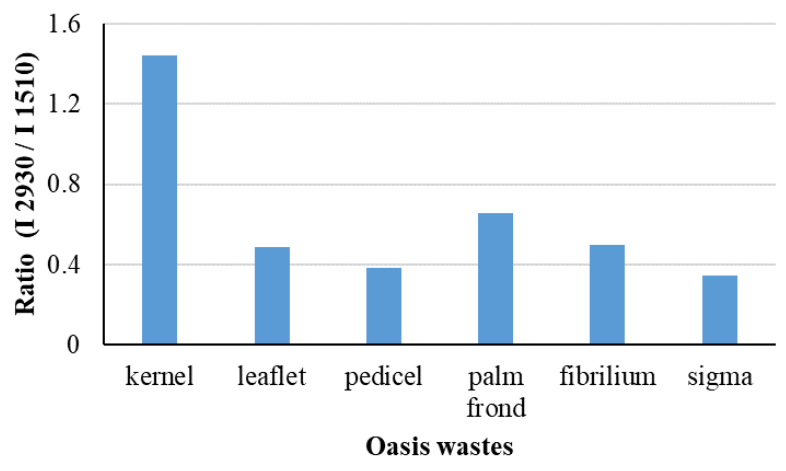

Fig. 5 Ratio of aliphatic signal to aromatic signal (I2930/I1510) of the obtained lignin FT-IR spectra

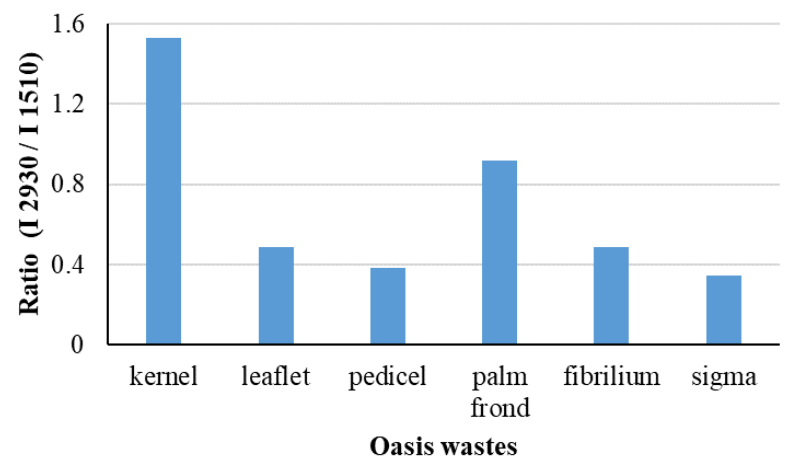

Fig. 6 Ratio of syringyl signal to guaicyl signal (I1325/I1263) of the obtained lignin FT-IR spectra

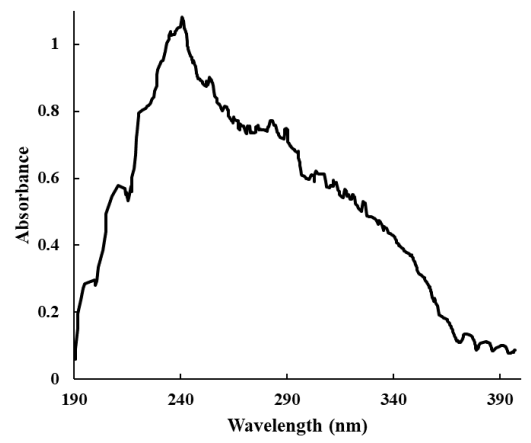

(a)

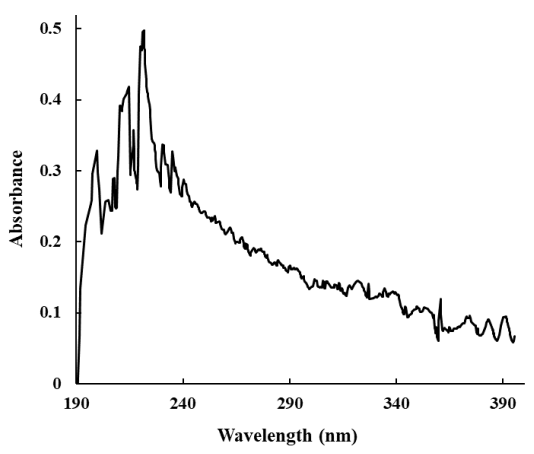

(c)

between $800-835 \mathrm{~cm}^{-1}$. These bands have strong intensity values for all lignin samples. This is due to the fact that the extracted lignin from the used DPW present a higher amount of syringyl units which corresponds to the bands recorded data showing maxima at 1600, 1460, 1110, and $1030 \mathrm{~cm}^{-1}$. Similar results were obtained by Popescu et al. [26].

\subsection{UV visible characterization of the extracted lignin from DPW}

Fig. 7 showed the UV-Vis spectra of the extracted lignin from the DPW. The occurrence of the maximum absorption at around $200 \mathrm{~nm}$, in these UV spectra, corresponds to the aromatic ring of the lignin structure. The bands with maxima in the range between 220-240 nm were assigned to the methoxylated phenol ring [25].

Based on these spectra, the position and the intensity of the peak reflect the contents of the syringyl and guaiacyl within the obtained lignin. According to SafouTchiami et al. [47] and Šurina et al. [49], syringyl has its maximum absorbance around 270-275 nm and guaiacyl approximately at $277-285 \mathrm{~nm}$. The absorbance levels, at the peak positions of syringyl and guaiacyl, for the obtained lignin showed little difference. This implies that our obtained lignin samples, from DPW, contain both

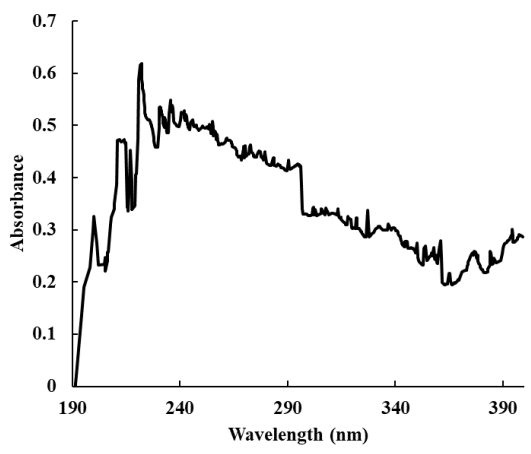

(b)

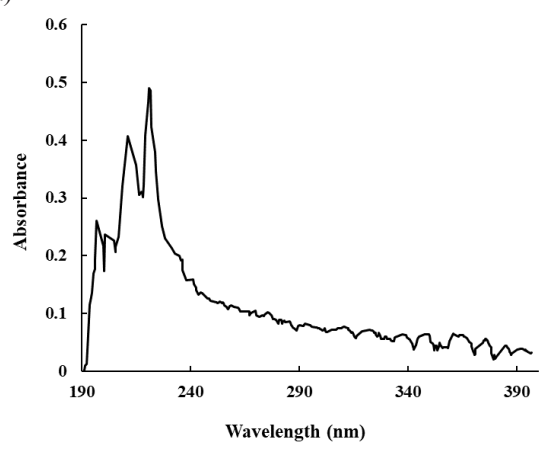

(d)

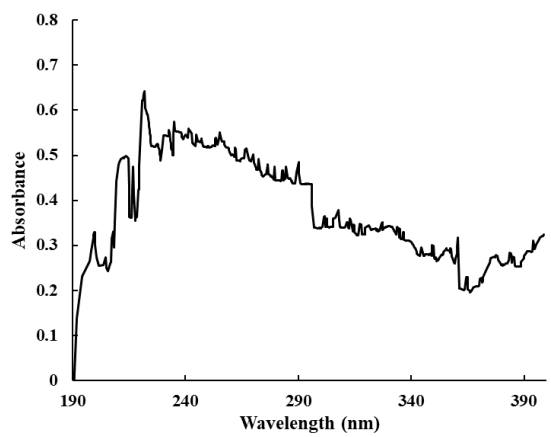

(e)

Fig. 7 UV-Vis spectra of (a) date palm kernel, (b) leaflet, (c) Pedicel, (d) palm frond, (e) fibrilium 
syringyl and guaiacyl and with a just over syringyl unit. The UV absorption bands are in accordance with FTIR results in which the content of syringyl and guaiacyl units are present in lignin extracted from fiber. This result was in concordance with literature results [26]. The lignin absorption from 300 to $400 \mathrm{~nm}$ is due to the aromatic ring bond conjugated with carbonyl groups [49].

The amount of non-conjugated, conjugated, and total phenolic hydroxyl groups are calculated according to Eqs. (2)-(4). As seen, the amount of non-conjugated phenolic ranged from $0.018 \mathrm{mmol} \mathrm{g}^{-1}$ for palm frond to $0.572 \mathrm{mmol} \mathrm{g}^{-1}$ for date palm kernel. The same trend was observed for the total content of phenolic hydroxyl groups. Thus, the raw material influenced both the number of individual groups (non-conjugated and conjugated) and consequently the total amount. The obtained value of the total amount of phenolic hydroxyl groups for the date palm kernel was almost equal to the value presented by Hattalli et al. [50]. For the other raw materials, the obtained values for the total content of phenolic hydroxyl groups were lower than that presented by Šurina et al. [49].

\subsection{Effects of extracted lignin on membrane properties \\ 3.5.1 Effects on contact angle}

Fig. 8 (a) shows the evolution of the water contact angle with the lignin percentage. As remarked, for all prepared membranes the contact angles are greater than $90^{\circ}$, therefore our membranes can be considered as hydrophobic. In addition, when the percentage of lignin in polymeric solution increases, a decrease of the contact angle of all prepared membranes is observed which induce a decrease of the hydrophobicity of membranes. The same evolution of membrane contact angle with lignin percentage can be observed in the study done by Yong et al. [51]. This decrease of the hydrophobicity of membranes with the increase of lignin content can be ascribed to the presence of abundant hydrophilic functional groups in the extracted lignin from the DPW. These hydrophilic functional groups are principally the hydroxyl groups, evidenced by the FT-IR peaks with high intensities at wavenumbers around $3350 \mathrm{~cm}^{-1}$ (Fig. 4). Using the UV-vis measurements, the extracted lignin from date palm kernel contains an amount of total phenolic hydroxyl more than the other lignin's. The hydrophobicity of the obtain membranes, prepared with lignin, are considerably reduced with a decrease of the contact angle from $126.9^{\circ}$ to $90.9^{\circ}$ when the lignin percentage is increased from 0.125 to $0.5 \%$. This evolution may be explained by the fact that the lignin migrates to the interface polymeric

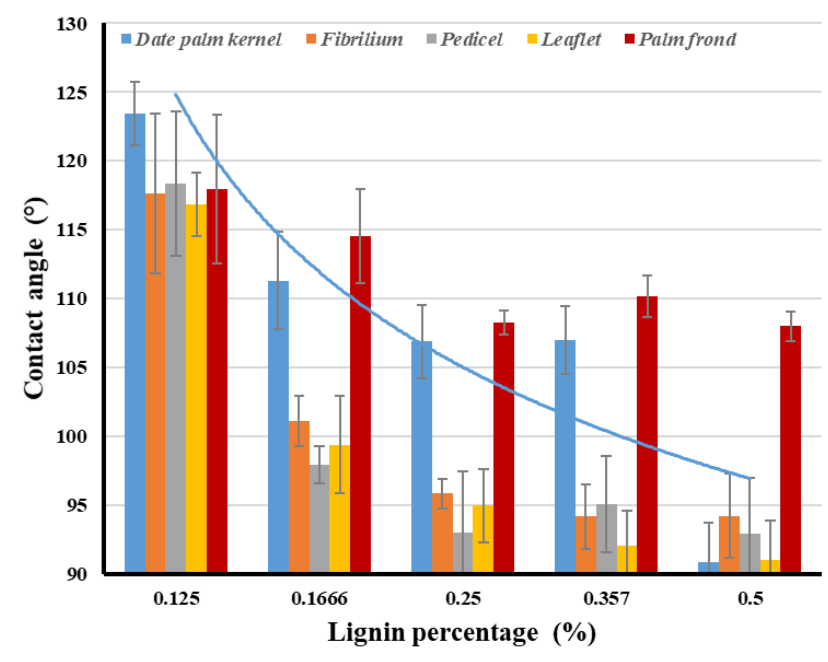

(a)

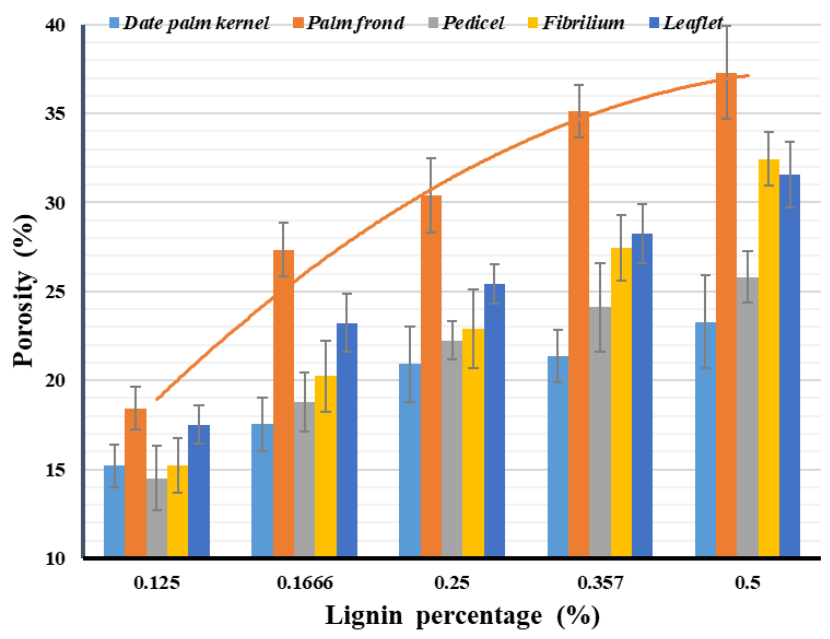

(b)

Fig. 8 Effect of lignin percentage on (a) membrane contact angle, (b) membrane porosity

solution/non-solvent during the phase inversion process. In this case, the density of the hydroxyl groups (hydrophilic groups) in the surface membrane increases which leads to the improvement of the membrane hydrophilicity [51].

\subsubsection{Effects on membrane porosity}

To elucidate the effects of adding the extracted lignin on membrane, porosity measurements were performed. In Fig. 8 (b), the obtained results show an improvement of all membrane porosity with the increase of the lignin percent in prepared membranes. These results are in line with the findings of Vilakati et al. [52]. This evolution can be explained by the fact that the addition of lignin, which plays the role of porogen in membrane preparation with the phase inversion process, generates more macrovoids in membrane sub-layer and consequently increases the membrane porosity [51]. 
The SEM images of cross-sections for fractured samples of the prepared membranes are shown in Fig. 9 (a)-(e). As seen, the variation of the lignin concentration in polymeric solution affects the structure of the cross-section of the waste LDPE/lignin membrane. When we have increased the lignin concentration from $0.125 \%$ to $0.5 \%$, the number of macrovoids in the membrane sublayer increased too, and the pore size rises with the lignin concentration in the polymeric solution. In addition, the prepared membranes are asymmetric. In fact and according to Fig. 9 (f), the top side of the membrane surface is dense but the bottom side is porous.

\section{Conclusion}

The present study includes the extraction of lignin from different DPW that are date palm kernel, leaflet, Pedicel, palm frond, and fibrilium using Klason method. Before the extraction of lignin, the raw material was analyzed. The results show that the content of holocellulose in the DPW was higher $(55.21 \%-67.29 \%)$ which allows the extraction of lignin to be faster. Besides, we obtained less quantity of ash in fibrilium $(1.86 \%)$ and palm frond $(1.96 \%)$. For the case of the extractive ingredients (waxes, fats, resins ...), the lowest percentage was for fibrilium (5.91\%), and the highest percentage was for leaflet $(10.07 \%)$. After extraction, the maximum lignin yield production was in palm frond $(31.63 \%)$ and the lower yield was in leaflet $(22.54 \%)$. The extracted lignins were characterized using FT-IR and UV-Vis. FT-IR characterization showed that the hydroxyl group appears in all lignin samples with high concentration. Also, and for all the extracted lignins, the content of aliphatic groups is a little bit higher than the aromatic groups. UV-Vis analysis shows that extracted lignins from DPW contain both syringyl and guaiacyl and with a slightly more syringyl unit. When the extracted lignins was added to a polymeric solution, modifications in membrane characteristics were remarked. Due to the numerous hydroxyl groups in the extracted lignins, we can notice an improvement of the hydrophilicity of the membrane, also a decrease of the contact angle by $28 \%$ when the lignin concentration increased from 0.125 to $0.5 \%$. Besides, an increase in the membrane porosity after the incorporation of the extracted lignins can be remarked. In the following work, these membranes will be used to treat oily wastewater and to see the effect of adding extracted lignin from DPW on the efficiency of membranes for this treatment.

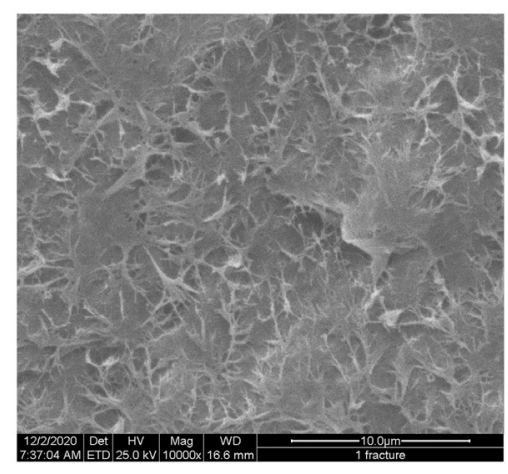

(a)

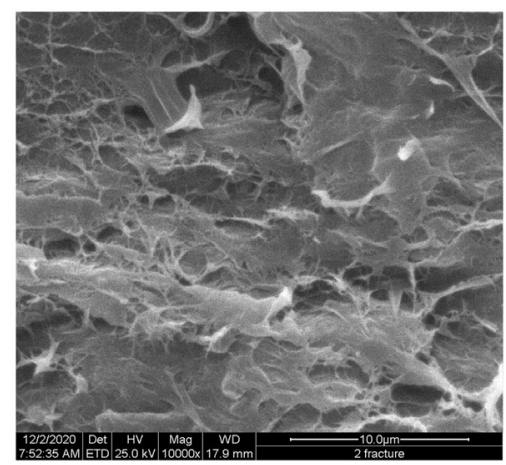

(d)

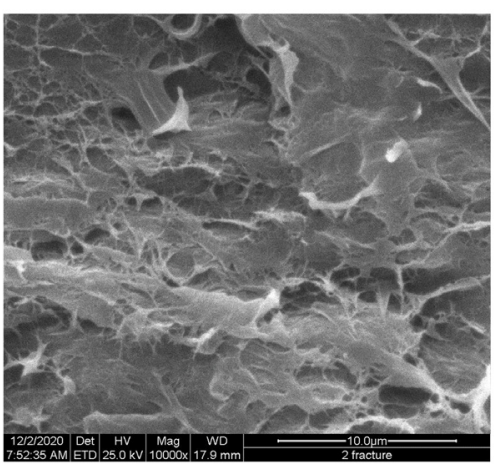

(b)

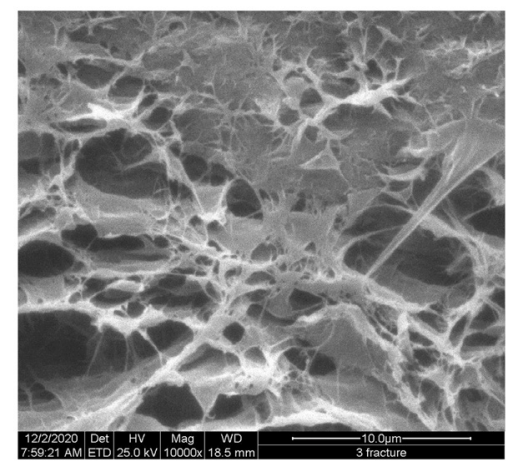

(e)

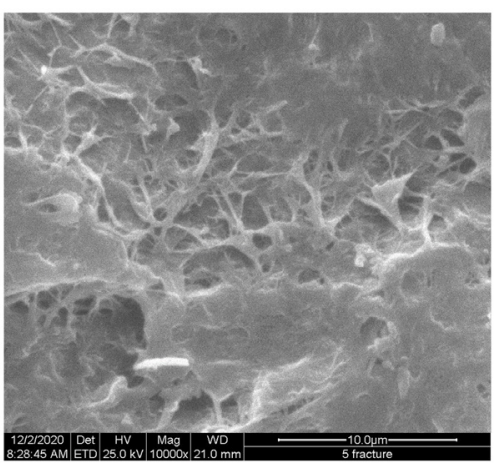

(c)

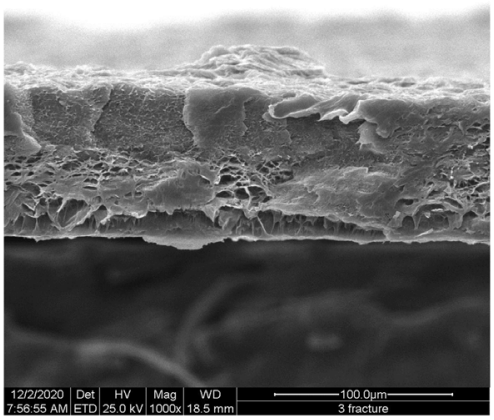

(f)

Fig. 9 SEM image of the cross-section of waste LDPE/Lignin membranes (a) $0.125 \%$, (b) $0.1666 \%$, (c) $0.25 \%$, (d) $0.375 \%$, (e) $0.5 \%$ ( $\times 10000)$ and (f) $0.5 \%(\times 1000)$ lignin concentration 


\section{References}

[1] Rhouma, A. "Le Palmier Dattier en Tunisie: I. Le patrimoine génétique" (The Date Palm in Tunisia: I. The genetic heritage), Volume 2, IPGRI, Rome, Italy, 2005. (in French)

[2] Chandrasekaran, M., Bahkali, A. H. "Valorization of date palm (Phoenix dactylifera) fruit processing by-products and wastes using bioprocess technology-Review", Saudi Journal of Biological Sciences, 20(2), pp. 105-120, 2013.

https://doi.org/10.1016/j.sjbs.2012.12.004

[3] Benabderrahim, M. A., Elfalleh, W., Belayadi, H., Haddad, M. "Effect of date palm waste compost on forage alfalfa growth, yield, seed yield and minerals uptake", International Journal of Recycling of Organic Waste in Agriculture, 7(1), pp. 1-9, 2018. https://doi.org/10.1007/s40093-017-0182-6

[4] Riggio, V., Rosso, M., Comino, E., Biagini, D., Montoneri, E. "Ecofriendly manure anaerobic digestion assisted by soluble biobased substances obtained from anaerobic digestion, composting and chemical hydrolysis of urban bio-wastes. A step toward the integration of urban and agriculture waste management", Journal of Chemical Technology and Biotechnology, 92(5), pp. 1111-1117, 2017. https://doi.org/10.1002/jctb.5106

[5] Lahouioui, M., Fois, M., Arfi, R. B., Ibos, L., Ghorbal, A. "Experimental Investigation of Palm Fiber Surface Treatment Effect on Thermal, Acoustical, and Mechanical Properties of a New Bio-Composite", In: Kallel, A., Ksibi, M., Ben Dhia, H., Khélifi, N. (eds.) Recent Advances in Environmental Science from the Euro-Mediterranean and Surrounding Regions, Springer International Publishing, Cham, Switzerland, 2018, pp. 1577-1579. https://doi.org/10.1007/978-3-319-70548-4

[6] Galiwango, E., Rahman, N. S. A., Al-Marzouqi, A. H., Abu-Omar, M. M., Khaleel, A. A. "Klason Method: An Effective Method for Isolation of Lignin Fractions from Date Palm Biomass Waste", Chemical and Process Engineering Research, 57, pp 46-58, 2018. [online] Available at: https://www.iiste.org/Journals/index.php/ CPER/article/view/41830/43079 [Accessed: 26 February 2021]

[7] Kálmán, G., Réczey, K. "Possible ways of bio-refining and utilizing the residual lignocelluloses of corn growing and processing", Periodica Polytechnica Chemical Engineering, 51(2), pp. 29-36, 2007.

https://doi.org/10.3311/pp.ch.2007-2.05

[8] Cusola, O., Rojas, O. J., Roncero, M. B. "Lignin Particles for Multifunctional Membranes, Antioxidative Microfiltration, Patterning, and 3D Structuring", ACS Applied Materials and Interfaces, 11(48), pp. 45226-45236, 2019.

https://doi.org/10.1021/acsami.9b16931

[9] Hu, X., Lee, W. H., Zhao, J., Bae, J. Y., Kim, J. S., Wang, Z., Yan, J., Zhuang, Y., Lee, Y. M. "Tröger's Base (TB)-containing polyimide membranes derived from bio-based dianhydrides for gas separations", Journal of Membrane Science, 610, Article number: 118255, 2020. https://doi.org/10.1016/j.memsci.2020.118255

[10] Shamaei, L., Khorshidi, B., Islam, M. A., Sadrzadeh, M. "Development of antifouling membranes using agro-industrial waste lignin for the treatment of Canada's oil sands produced water", Journal of Membrane Science, 611, Article number: 118326, 2020.

https://doi.org/10.1016/j.memsci.2020.118326
[11] Rossberg, C., Janzon, R., Saake, B., Leschinsky, M. "Effect of Process Parameters in Pilot Scale Operation on Properties of Organosolv Lignin", BioResources, 14(2), pp. 4543-4559, 2019.

[12] Hochegger, M., Cottyn-Boitte, B., Cézard, L., Schober, S., Mittelbach, M. "Influence of Ethanol Organosolv Pulping Conditions on Physicochemical Lignin Properties of European Larch", International Journal of Chemical Engineering, 2019, pp. 1-10, 2019. https://doi.org/10.1155/2019/1734507

[13] Fodil Cherif, M., Trache, D., Brosse, N., Benaliouche, F., Tarchoun, A. F. "Comparison of the Physicochemical Properties and Thermal Stability of Organosolv and Kraft Lignins from Hardwood and Softwood Biomass for Their Potential Valorization", Waste and Biomass Valorization, 11(12), pp. 6541-6553, 2020. https://doi.org/10.1007/s12649-020-00955-0

[14] Horst, D. J., Behainne, J. J. R., de Andrade Júnior, P. P., Kovaleski, J. L. "An experimental comparison of lignin yield from the Klason and Willstatter extraction methods", Energy for Sustainable Development, 23, pp. 78-84, 2014.

https://doi.org/10.1016/j.esd.2014.07.005

[15] Muzakir, M. M., Nwosu, F. O., Amusat, S. O. "Mild Steel Corrosion Inhibition in a $\mathrm{NaCl}$ Solution by Lignin Extract of Chromolaena odorata", Portugaliae Electrochimica Acta, 37(6), pp. 359-372, 2019. https://doi.org/10.4152/pea.201906359

[16] Yearla, S. R., Padmasree, K. "Preparation and characterisation of lignin nanoparticles: evaluation of their potential as antioxidants and UV protectants", Journal of Experimental Nanoscience, 11(4), pp. 289-302, 2016.

https://doi.org/10.1080/17458080.2015.1055842

[17] Kuzminova, A. I., Dmitrenko, M. E., Poloneeva, D. Y., Selyutin, A. A., Mazur, A. S., Emeline, A. V., Mikhailovskii, V. Y., Solovyev, N. D., Ermakov, S. S., Penkova, A. V. "Sustainable composite pervaporation membranes based on sodium alginate modified by metal organic frameworks for dehydration of isopropanol", Journal of Membrane Science, 626, Article number: 119194, 2021. https://doi.org/10.1016/j.memsci.2021.119194

[18] Tham, H. M., Chung, T.-S. "One-step cross-linking and tannic acid modification of polyacrylonitrile hollow fibers for organic solvent nanofiltration", Journal of Membrane Science, 610, Article number: 118294, 2020. https://doi.org/10.1016/j.memsci.2020.118294

[19] Park, S.-H., Alammar, A., Fulop. Z., Pulido, B. A., Nunes, S. P., Szekely, G. "Hydrophobic thin film composite nanofiltration membranes derived solely from sustainable sources", Green Chemistry, 23(3), pp. 1175-1184, 2021. https://doi.org/10.1039/D0GC03226C

[20] Alabi, O., Olanrewaju, A. A., Afolabi, T. J. "Process optimization of adsorption of $\mathrm{Cr}$ (VI) on adsorbent prepared from Bauhinia rufescens pod by Box-Behnken Design", Separation Science and Technology, 55(1), pp. 47-60, 2020. https://doi.org/10.1080/01496395.2019.1577436

[21] Wei, Y., Shen, C., Xie, J., Bu, Q. "Study on reaction mechanism of superior bamboo biochar catalyst production by molten alkali carbonates pyrolysis and its application for cellulose hydrolysis", Science of The Total Environment, Article number: 136435, 2020. https://doi.org/10.1016/j.scitotenv.2019.136435 
[22] Fuad, M. Y. A., Yaakob, I., Ishak, Z. A. M., Omar, A. K. M. "Density measurement of rice husk ash filler particles in polypropylene composites", Polymer Testing, 12(2), pp. 107-112, 1993. https://doi.org/10.1016/0142-9418(93)90033-L

[23] Horst, D. J., Behainne, J. J. R., de Andrade Junior, P. P., Serpe, L. F. "Assessing the lignin fraction extracted from Brazilian energy crops", American Journal of Environmental Sciences, 11(1), pp. 46-54, 2015.

https://doi.org/10.3844/ajessp.2015.46.54

[24] Braga, R. M., Queiroga, T. S., Calixto, G. Q., Almeida, H. N., Melo, D. M. A., Melo, M. A. F., Freitas, J. C. O., Curbelo, F. D. S. "The energetic characterization of pineapple crown leaves", Environmental Science and Pollution Research, 22(23), pp. 18987-18993, 2015. https://doi.org/10.1007/s11356-015-5082-6

[25] Latif, M. H. A., Attiya, H. G., Al-Abayaji, M. A. "Lignin FT-IR study of Iraqi date palm Phoenix dactylifera frond bases wood", Plant Archives, 19(Suppl. 2), pp. 327-332, 2019. [online] Available at: http://plantarchives.org/SPL\%20ISSUE\%20SUPP\%202,2019/ 60\%20(327-332).pdf [Accessed: 21 April 2020]

[26] Popescu, C.-M., Vasile, C., Popescu, M.-C., Singurel, G., Popa, V. I., Munteanu, B. S. "Analytical methods for lignin characterization. II. Spectroscopic studies", Cellulose Chemistry and Technology, 40(8), pp. 597-621, 2006.

[27] Jablonsky, M., Kočiš, J., Ház, A., Šima, J. "Characterization and comparison by UV spectroscopy of precipitated lignins and commercial lignosulfonates", Cellulose Chemistry and Technology, 49(3-4), pp. 267-274, 2015. [online] Available at: https://www. cellulosechemtechnol.ro/pdf/CCT3-4(2015)/p.267-274.pdf [Accessed: 20 April 2020]

[28] Zrelli, A., Chaouachi, B. "Modeling and simulation of a vacuum membrane distillation plant coupled with solar energy and using helical hollow fibers", Brazilian Journal of Chemical Engineering, 36(3), pp. 1119-1129, 2019. https://doi.org/10.1590/0104-6632.20190363s20180531

[29] Ajari, H., Zrelli, A., Chaouachi, B., Pontié, M. "Preparation and Characterization of Hydrophobic Flat Sheet Membranes Based on a Recycled Polymer", International Polymer Processing, 34(3), pp. 376-382, 2019.

https://doi.org/10.3139/217.3717

[30] Alsalhy, Q. F., Ibrahim, S. S., Hashim, F. A. "Experimental and theoretical investigation of air gap membrane distillation process for water desalination", Chemical Engineering Research and Design, 130, pp. 95-108, 2018.

https://doi.org/10.1016/j.cherd.2017.12.013

[31] Salomón-Torres, R., Sol-Uribe, J. A., Valdez-Salas, B., GarcíaGonzález, C., Krueger, R., Hernández-Balbuena, D., NorzagarayPlasencia, S., García-Vázquez, J. P., Ortiz-Uribe, N. "Effect of Four Pollinating Sources on Nutritional Properties of Medjool Date (Phoenix dactylifera L.) Seeds", Agriculture, 10(2), Article number: 45, 2020. https://doi.org/10.3390/agriculture10020045

[32] Li, W.-C., Han, L.-J., Peng, T.-B., Xie, Y.-Y., Zou, Y., Li, L.-Z., Jia, S.-R., Zhong, C. "Structural and behavior changes of herbaceous and hardwood biomass during steam explosion pretreatment and enzymatic hydrolysis", BioResources, 15(1), pp. 691-705, 2020. https://doi.org/10.15376/biores.15.1.691-705
[33] Hossain, M. Z., Waly, M. I., Singh, V., Sequeira, V., Rahman, M. S. "Chemical Composition of Date-Pits and Its Potential for Developing Value-Added Product - a Review", Polish Journal of Food and Nutrition Sciences, 64(4), pp. 215-226, 2014. https://doi.org/10.2478/pjfns-2013-0018

[34] Kolawole, S. A., Abdullahi, D., Dauda, B. M., Ishiaku, U. S. "Physico-Mechanical Properties of Dates Palm (Phoenix dactylifera) Pits Reinforced Unsaturated Polyester Composites", International Journal of Science and Research (IJSR), 4(10), pp. 1412-1418, 2015. [online] Available at: https://www.ijsr.net/ search_index_results_paperid.php?id=SUB158750 [Accessed: 23 April 2020]

[35] Almi, K., Benchabane, A., Lakel, S., Kriker, A. "Potential utilization of date palm wood as composite reinforcement", Journal of Reinforced Plastics and Composites, 34(15), pp. 1231-1240, 2015. https://doi.org/10.1177/0731684415588356

[36] Bousdira, K., Bousdira, D., Bekkouche, S. M. E. A., Yahiaoui, F. Z., Nouri, L., Legrand, J. "Combustion Study of Phoenicicole Biomass in Algerian Oasis Using Thermogravimetric Analysis: Deglet Nour Cultivar Case", Arabian Journal for Science and Engineering, 43(5), pp. 2299-2308, 2018.

https://doi.org/10.1007/s13369-017-2723-8

[37] Bouchelta, C., Medjram, M. S., Bertrand, O., Bellat, J.-P. "Preparation and characterization of activated carbon from date stones by physical activation with steam", Journal of Analytical and Applied Pyrolysis, 82(1), pp. 70-77, 2008.

https://doi.org/10.1016/j.jaap.2007.12.009

[38] Crini, G., Badot, P.-M. "Sorption processes and pollution: Conventional and non-conventional sorbents for pollutant removal from wastemasters", Presses Universitaires de Franche-Comté, Besançon, France, 2011.

[39] Pecha, B., Garcia-Perez, M. "Pyrolysis of Lignocellulosic Biomass", In: Dahiya, A. (ed.) Bioenergy: Biomass to biofuels, Elsevier, Amsterdam, Netherlands, 2015, pp. 413-442. https://doi.org/10.1016/B978-0-12-407909-0.00026-2

[40] Chaari, R., Khlif, M., Mallek, H., Bradai, C., Lacoste, C., Belguith, H., Tounsi, H., Dony, P. "Enzymatic treatments effect on the poly (butylene succinate)/date palm fibers properties for bio-composite applications", Industrial Crops and Products, 148, Article number: 112270, 2020.

https://doi.org/10.1016/j.indcrop.2020.112270

[41] Senthil Kumar, P., Yaashikaa, P. R. "Sources and operations of waste biorefineries", In: Praveen Kumar, R., Gnansounou, E., Raman, J. K., Baskar, G. (eds.) Refining Biomass Residues for Sustainable Energy and Bioproducts, Elsevier, Amsterdam, Netherlands, 2020, pp. 111-133. https://doi.org/10.1016/B978-0-12-818996-2.00005-3

[42] Jabli, M., Saleh, T. A., Sebeia, N., Tka, N., Khiari, R. "Dimethyl diallyl ammonium chloride and diallylamin Co-polymer modified bio-film derived from palm dates for the adsorption of dyes", Scientific Reports, 7(1), Article number: 14448, 2017. https://doi.org/10.1038/s41598-017-14327-7

[43] Demirbaş, A. "Relationships between lignin contents and heating values of biomass", Energy Conversion and Management, 42(2), pp. 183-188, 2001.

https://doi.org/10.1016/S0196-8904(00)00050-9 
[44] Shrivastava, P., Khongphakdi, P., Palamanit, A., Kumar, A., Tekasakul, P. "Investigation of physicochemical properties of oil palm biomass for evaluating potential of biofuels production via pyrolysis processes", Biomass Conversion and Biorefinery, 2020. https://doi.org/10.1007/s13399-019-00596-x

[45] da Silva, S. B., Arantes, M. D. C., de Andrade, J. K. B., Andrade, C. R., Carneiro, A. de C. O., Protásio, T. de P. "Influence of physical and chemical compositions on the properties and energy use of lignocellulosic biomass pellets in Brazil", Renewable Energy, 147(1), pp. 1870-1879, 2020. https://doi.org/10.1016/j.renene.2019.09.131

[46] Li, T., Takkellapati, S. "The current and emerging sources of technical lignins and their applications", Biofuels, Bioproducts and Biorefining, 12(5), pp. 756-787, 2018. https://doi.org/10.1002/bbb.1913

[47] Safou-Tchiama, R., Barhé, T. A., Soulounganga, P., Akagah, A. G., De Jeso, B. "A comparative study of the syringyl, guaiacyl and hydroxyl groups units distribution in some African tropical hardwoods' lignin by Py-GC/MS and spectroscopic techniques", Journal of Materials and Environmental Sciences, 8(7), pp. 2530-2540, 2017. [online] Available at: https://www.jmaterenvironsci.com/Document/vol8/ vol8_N7/272-JMES-2734-Tchiama.pdf [Accessed: 15 April 2020]

[48] Zhang, J., Wu, C., Yu, D., Zhu, Y. "Structural Characterization of Soluble Lignin in the Pre-Hydrolysis Liquor of Bamboo-willow Dissolving Pulp", BioResources, 15(1), pp. 825-839, 2020. https://doi.org/10.15376/biores.15.1.825-839
[49] Šurina, I., Jablonskỳ, M., Ház, A., Sladková, A., Briškárová, A., Kačík, F., Šima, J. "Characterization of Non-wood Lignin Precipitated with Sulphuric Acid of Various Concentrations", BioResources, 10(1), pp. 1408-1423, 2015. [online] Available at: https://ojs.cnr.ncsu.edu/ index.php/BioRes/article/view/BioRes_10_1_1408_Surina_Non Wood_Lignin_Precipitated_Sulphuric_Acid[Accessed:02 May 2020]

[50] Hattalli, S., Benaboura, A., Ham-Pichavant, F., Nourmamode, A., Castellan, A. "Adding value to Alfa grass (Stipa tenacissima L.) soda lignin as phenolic resins 1. Lignin characterization", Polymer Degradation and Stability, 76(2), pp. 259-264, 2002. https://doi.org/10.1016/S0141-3910(02)00022-8

[51] Yong, M., Zhang, Y., Sun, S., Liu, W. "Properties of polyvinyl chloride (PVC) ultrafiltration membrane improved by lignin: Hydrophilicity and antifouling", Journal of Membrane Science, 575, pp. 50-59, 2019. https://doi.org/10.1016/j.memsci.2019.01.005

[52] Vilakati, G. D., Hoek, E. M. V., Mamba, B. B. "Probing the mechanical and thermal properties of polysulfone membranes modified with synthetic and natural polymer additives", Polymer Testing, 34, pp. 202-210, 2014.

https://doi.org/10.1016/j.polymertesting.2014.01.014 